\title{
Palatal tremor as a manifestation of posterior circulation haemorrhagic stroke
}

\author{
Saed Alnaimat, ${ }_{1}^{1}$ Raghav Chandra, ${ }^{2}$ Shweta Gupta, ${ }^{3}$ Benjamin Mba ${ }^{4}$
}

'Graduate College, Rush University, Chicago, Illinois, USA ${ }^{2}$ Medical College, Rush University Medical Center, Chicago, Illinois, USA ${ }^{3}$ Department of HematologyOncology, John H Stroger Jr Hospital of Cook County, Chicago, Illinois, USA

${ }^{4}$ Department of Medicine, John H Stroger Jr Hospital of Cook County, Chicago, Illinois, USA

\section{Correspondence to}

Dr Saed Alnaimat,

saed_alnaimat@rush.edu

Accepted 25 April 2018

\section{DESCRIPTION}

Palatal tremor (previously called palatal myoclonus) is an extremely rare movement disorder characterised by involuntary, rhythmic contractions of the palatal muscles. Due to its rarity, this cryptic neurological finding is practically challenging to discover, and often missed by clinicians unless specifically looked for during physical examination.

Palatal tremor was first described by Politzer in 1862. Its prevalence data are lacking in the literature, with only a few hundred cases reported. The most notable pathological change is hypertrophic degeneration of the inferior olivary nuclei, which are presumed to be the pacemaker of symptomatic palatal tremor. The rhythmic inferior olivary activity is transmitted to the brainstem reticular centres controlling bulbar and limb functions. ${ }^{1}$

Two forms of palatal tremor have been described: essential and symptomatic. The aetiology of essential palatal tremor remains unclear. It can be idiopathic or psychogenic, but without any focal lesions on brain imaging. In essential palatal tremor, ear clicks or pulsatile tinnitus are usually the sole manifestations. These are caused by contractions of the tensor veli palatini muscle leading to opening and closing of the Eustachian tube. On the other hand, symptomatic palatal tremor is associated with brainstem or cerebellar lesions like cerebrovascular disease, degenerative diseases, multiple sclerosis, tumours and trauma. In symptomatic palatal tremor, the levator veli palatini muscle is usually involved, but ear clicks are usually absent. In 1990, Deuschl et al ${ }^{1}$ reported 287 cases with palatal tremor, including 210 cases with symptomatic palatal tremor and 77 cases with essential palatal tremor. Cerebrovascular disease was present in 55\% of patients with symptomatic palatal tremor. ${ }^{1}$ In our case, the patient had a bilateral cerebellar haemorrhage. Subsequently, he developed this very interesting physical exam finding named palatal tremor (video 1). The patient

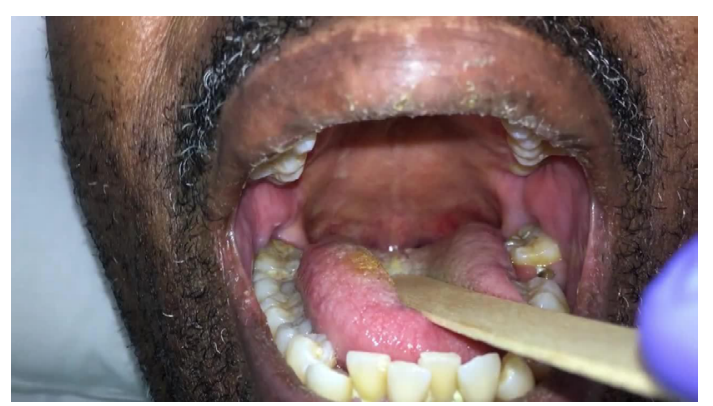

Video 1 Video shows involuntary rhythmic contractions of the palatal muscles, the so-called palatal tremor.

\section{Learning points}

- Palatal tremor is an extremely rare movement disorder caused by hypertrophic degeneration of the inferior olivary nucleus.

- This cryptic neurological finding should specifically be looked for in patients with posterior circulation stroke.

- Treatment is targeted for patients who experience symptoms from palatal tremor.

- Treatment options vary from botulinum toxin injection to radiofrequency ablation, or microvascular surgery in certain cases.

did not report any symptoms of palatal tremor. However, he was left with residual right-sided haemiparesis, dysarthria, and urinary and faecal incontinence. Although psychogenic palatal tremor has been noted in the literature, our patient had no history of previous psychiatric comorbidities. Furthermore, the presence of palatal tremor in the setting of a known bilateral cerebellar haemorrhage provides overwhelming evidence that our patient had a neurophysiological manifestation of posterior circulation insult, the so-called symptomatic palatal tremor.

Suggested treatment options for palatal tremor include anticonvulsants and benzodiazepines, but these are usually associated with disappointing effects. Injection of botulinum toxin into the palatal muscles has been successful in a few published case reports and series. ${ }^{2}$ Surgical therapies have included Eustachian tube obliteration and ventilation tube placement. Transection of the levator veli palatini and tensor veli palatini muscles has been proposed, but this operation is destructive and may also lead to Eustachian tube dysfunction. Microvascular surgery, however, may be effective for palatal tremor caused by brainstem compression by the vertebral artery. In addition, targeted radiofrequency ablation of the levator veli palatini and tensor veli palatini muscles has been attempted with some promising results. ${ }^{3}$ In our patient, however, no treatment was sought for palatal tremor since the patient had no complaints of ear clicking or pulsatile tinnitus.

Contributors SA: direct patient care and video recording. RC: literature review and grammar corrections. SG: abstract structure and flow. BM: overall mentorship and supervision.

Funding The authors have not declared a specific grant for this research from any funding agency in the public, commercial or not-for-profit sectors. 
Competing interests None declared.

\section{Patient consent Obtained.}

Provenance and peer review Not commissioned; externally peer reviewed.

(C) BMJ Publishing Group Ltd (unless otherwise stated in the text of the article) 2018. All rights reserved. No commercial use is permitted unless otherwise expressly granted.

\section{REFERENCES}

1 Deuschl G, Mischke G, Schenck E, et al. Symptomatic and essential rhythmic palatal myoclonus. Brain 1990;113:1645-72.

2 Anis MM, Pollak N. Case report treatment of palatal myoclonus with botulinum toxin injection. Case reports in otolaryngology 2013;2013:10-3.

3 Aydin 0, Iseri M, Ozturk M. Radiofrequency ablation in the treatment of idiopathic bilateral palatal myoclonus: a new indication. Ann Otol Rhinol Laryngol 2006;115:824-6.

Copyright 2018 BMJ Publishing Group. All rights reserved. For permission to reuse any of this content visit http://group.bmj.com/group/rights-licensing/permissions.

BMJ Case Report Fellows may re-use this article for personal use and teaching without any further permission.

Become a Fellow of BMJ Case Reports today and you can:

- Submit as many cases as you like

- Enjoy fast sympathetic peer review and rapid publication of accepted articles

- Access all the published articles

- Re-use any of the published material for personal use and teaching without further permission

For information on Institutional Fellowships contact consortiasales@bmjgroup.com

Visit casereports.bmj.com for more articles like this and to become a Fellow 